\title{
Disorders of gender identity
}

\author{
James Barrett
}

\begin{abstract}
SUMMARY
Gender identity disorders are not common. The most frequent is dual-role transvestism, but it rarely needs medical attention. The least frequent is transsexualism. Transsexualism is not usually indicative of serious psychopathology. Diagnoses should be made by a gender identity clinic and never by the patient, and a clear change of gender role should precede any hormone treatment. $\mathrm{Pa}$ tients must have lived and thrived entirely in their new gender role for at least 2 years before any genital surgery is undertaken. However, bilateral mastectomy might be considered for females after a year of life in a male role. With these selection criteria, the outcomes of surgery are generally good. In the UK, individuals may legally change their recorded sex, usually after gender reassignment treatment.
\end{abstract}

\section{DECLARATION OF INTEREST}

None.

Disorders of gender identity involve a greater number of disciplines than most other areas of psychiatry. ${ }^{a}$ Endocrinologists, speech and language therapists, and surgeons (ears, nose and throat, plastic and urological) are routinely involved. Further, the field is highly politicised, attracting much public fascination and arousing strong opinions.

Disorders of gender identity have probably always existed, inside and outside Europe (Heiman 1975). It seems that the incidence of transsexualism is very roughly 1 in 60000 males and 1 in 100000 females, and it seems to have remained constant (Landen 1996). There is the suggestion that there may be a raised rate in Polynesians, possibly related to a greater incidence of partial androgen insensitivity syndromes (H. Bower, personal communication, 2002).

\section{Classification}

Currently, in ICD-10 (World Health Organization 1992), disorders of gender identity are classified not as mental illnesses but as disorders of adult personality and behaviour (Box 1).

Whether transvestism is contiguous with transsexualism or distinct from it is a debate that has endured over the decades (Buhrich 1977). The current diagnostic position, including dual-role transvestism but not fetishistic transvestism as a gender identity disorder, reflects this uncertainty.

Important differential diagnoses include fetishistic transvestism, dysmorphophobia, autogynaephilia and some other personality or sexuality disorders. Occasionally, psychoses present in such a way as to resemble a gender identity disorder and, increasingly rarely, gay men or lesbians may present as transsexual (Shtasel 1979).

Transsexualism is described in ICD-10 as 'a desire to live and be accepted as a member of the opposite sex, usually accompanied by a sense of discomfort with [...] one's anatomic sex' (World Health Organization 1992). For the diagnosis to be made, transsexual identity should have been present for at least 2 years, and must not be a symptom of another mental disorder (e.g. schizophrenia) or associated with any endocrine or chromosome abnormality.

This last stipulation implies that there is never a hormonal or genetic element in transsexualism and that any such abnormality, if present, would always account for the cross-gender identity. It should be noted that either or both of these implications may well be without foundation.

\section{Aetiology}

Disorders of gender identity are of obscure origin. Initially, hypotheses about causation addressed psychological factors and came mostly from a psychoanalytic perspective (Lothstein 1981). However, over the decades, what evidence there is has suggested a multifactorial aetiology, with biological factors rising in relative importance.

There is a raised rate of disorders of gender identity in people with Kleinfelter syndrome, and children with gender identity disorders

\section{BOX 1 ICD-10 classification of gender identity disorders}

- F64.0 Transsexualism

- F64.1 Dual-role transvestism

- F64.2 Gender identity disorder of childhood

- F64.8 Other gender identity disorders

- F64.9 Gender identity disorder, unspecified

(World Health Organization 1992)
James Barrett is lead clinician at the Charing Cross National Gender Identity Clinic. Over the past 25 years he has seen around 9000 people with disorders of gender identity. Correspondence James Barrett, Charing Cross National Gender Identity Clinic, 179-183 Fulham Palace Road, London W6 80Z, UK. Email: james.barrett@ wlmht.nhs.uk

a. Throughout this article the terms 'male' and 'female' refer to biological sex assigned at birth. 
are more likely to have attracted a diagnosis of autism-spectrum disorder; the latter is suspected to be true of adults as well (Green 1995). Males with disorders of gender identity are more likely than chance would allow to be left-handed (Green 1995). Their family trees show a relative lack of maternal uncles, and they are more likely to be lower down a male birth order (i.e. younger than any other brothers). One hypothesis arising from these findings supposes that in these families, women mount an immune response to a Y chromosome in pregnancy, the titre rising with each successive male pregnancy (Green 1995).

A single, small, post-mortem brain study showed a female-sized bed nucleus of the stria terminalis in males with transsexualism (Seal 2007). Although interesting, this study had no control group of homosexual males without gender identity disorder, and the finding might have been caused by earlier treatment with hormones.

It should be noted that many of these curious findings do nothing to address the genesis of gender identity disorders in females. In their case there is the clinical suspicion that polycystic ovarian syndrome rates may be raised, but this remains statistically unproven (Seal 2007).

There is still no overarching hypothesis that draws these disparate findings together. This might, of course, simply reflect a multifactorial aetiology.

\section{Differential diagnosis}

There is a public and to some extent a general psychiatric perception that transsexualism is the only or at least the main disorder of gender identity. This is illusory (Levine 1980), but the illusion persists in part because most dual-role transvestites do not come to the attention of psychiatric services. Certainly, transsexualism is the diagnosis for which most treatment evidence is available. There is little research into dual-role transvestism, nor much into dysmorphophobia or autogynaephilia presenting as or relating to a gender identity disorder (Blanchard 1991, 1993a,b,c,d), even though these are important differential diagnoses and there is the suggestion that non-transsexual disorders of gender identity are more associated with psychopathology (Miach 2000). These differential diagnoses may require different management to transsexualism (Blanchard 1989).

In the past, problems with gender identity were thought to represent severe mental illness. Most of the abnormalities identified were personality disorders, but a significant proportion of patients were thought to have schizophrenia (Cole 1997).
Larger, more recent studies show that less than $10 \%$ have problems associated with mental illness, genital mutilation or suicide attempts (Cole 1997). Over the past decade, clinic-based studies have generally supported the view that transsexualism is usually an isolated diagnosis and not part of any general psychopathological disorder (Haraldsen 2000). Similar results are suggested in adolescents, supporting the idea that major psychopathology is not required for the development of transsexualism (Smith 2001). It seems that the earlier findings might have represented a sampling bias.

Nevertheless, the inference in the current diagnostic classification that other psychiatric disorders be excluded may mean that the populations actually referred to gender identity clinics have been filtered, causing an artificially lower rate of psychopathology in these clinic populations and thus falsely suggesting the low rate of psychiatric comorbidity.

\section{Transsexualism}

Transsexualism has several important differential diagnoses, all of which may cause gender dysphoric feelings.

Some gay men and lesbians present with claims of transsexualism (Shtasel 1979; Barrett 2007a) and have no psychiatric diagnosis. The most frequent formal differential diagnosis is of transvestism (dual-role or fetishistic), but others include psychoses and mood disorders (Barrett 2007a).

\section{Autogynaephilia}

Autogynaephilia may also present. This is the state of being sexually aroused by the idea of having both male and female sexual attributes (usually breasts and a penis). Males with autogynaephilia usually seek oestrogen treatment to eliminate this effect. Such treatment diminishes the libido that gives rise to the very desire itself, and autogynaephilia may wane over time, only to be replaced by another unusual sexual drive. For these reasons, autogynaephilia is not usually an indication for oestrogen treatment (Barrett 2007a).

\section{Partial androgen insensitivity syndromes}

Rarely, partial androgen insensitivity syndromes may cause cross-gender identification and males with these syndromes would qualify for a diagnosis of gender identity disorder (not otherwise specified) because there is an abnormality of endocrine function. These syndromes can only be detected with the endocrine expertise and complex pathological testing offered by a gender 
identity clinic. They cannot be detected if hormone treatment has already started. The presence of a partial androgen insensitivity syndrome does not greatly alter the subsequent management of the affected patient but is important because, as inherited conditions, they may affect the sons of the patient's sisters. Genetic counselling may be indicated (Seal 2007).

\section{Treatment}

Treatment is drastic and irreversible, so it should only be undertaken in a setting of diagnostic certainty. It is a cardinal principle in a gender identity clinic that reversible changes should precede irreversible changes and that no step should be undertaken unless the preceding steps have been accompanied by psychological and social improvement (Box 2).

\section{Diagnosis}

The least certain diagnosis is that made by the patient, made as it is without any training or objectivity. This uncertainty is not lessened by the patient's frequently high degree of conviction. Neither does the support of others with gender dysphoria help, since conviction leads people to associate with the like-minded and to discount or fail to seek out disharmonious views.

Local psychiatric services are only slightly better placed to make a diagnosis, having greater objectivity but often not much experience or training. Accordingly, diagnoses should properly be made by gender identity clinics. Internationally accepted guidelines stipulate that at least two experienced diagnostic opinions are required before anyone should undergo gender reassignment surgery. It seems sensible to have the same degree of safety in the earlier stages of treatment, because a diagnosis leading to a change of social gender role has serious social implications, and hormone treatments (particularly in females) have irreversible effects.

B0X 2 Steps towards changing gender role

- Change in social gender role/real-life experience

- Hormone therapy high-dose oestrogen androgen therapy

- Surgery mastectomy gender reassignment

- Psychological support throughout each step
People who present at a gender identity clinic usually state that they have transsexualism and seek immediate treatment with hormones, surgery or both. They may arrive at this point from any of a number of rather distinct earlier trajectories.

\section{Patient history}

Considering male patients in whom differential diagnoses have been excluded, the most common history is that of earlier dual-role transvestism, often preceded by fetishistic transvestism. Such sexual interest as there is (it is usually slight) is directed towards females. As time passes, the patient begins to feel fake and unreal in a male rather than a female role (Barrett 2007a), they remain sexually interested in women and see themselves as lesbians.

A smaller proportion of male patients would earlier have been seen by others and themselves as feminine gay men, again with a low libido, with a liking for wearing female clothes. As time passes, their femininity grows and they begin to feel more female than feminine, and to be treated as such in gay male circles (Barrett 2007a).

Female patients often give a history of having earlier been viewed by others, and less often by themselves, as masculine lesbians. Their sense of masculinity becomes so overwhelming that they come to identify as male. If they had previously eschewed male company or associations for feminist political reasons, a change of social gender role may denude such patients of much of their social circle (Barrett 2007a).

A small number of female patients show a sexual preference for males, but they are interested in gay men, and identify as such themselves (Barrett 2007a).

A small proportion of patients seem to have displayed a sense of cross-gender identification from their earliest years, and either attracted or would have attracted a diagnosis of childhood gender identity disorder. Many patients make this claim, only for documentary evidence or the testimony of their relatives to refute it, or alter it to a history of childhood tomboyism or unmasculinity, which is a very different matter (Barrett 2007a).

\section{Children and adolescents}

Children and adolescents with gender identity disorders pose particular problems. Instinctive caution has led to surgery and hormones being delayed, although Dutch evidence is that with carefully selected patients, early surgical intervention carries a good outcome (CohenKettenis 1997). There is now a UK trend towards postponing puberty by means of gonadotropin- 
releasing hormone analogues and introducing cross-gender hormone treatment when the child is able to give valid consent. There is the suggestion that for males earlier age at onset of transsexualism was associated with better outcome (Blanchard 1989), which may reflect 'core' transsexualism.

The issue of whether to intervene early is rendered more problematic by a study which followed up ten feminine boys, of whom only one became transsexual and four heterosexual, suggesting that a proportion of those with a good outcome in Holland would, under UK protocols, have developed into unremarkable young gay people. It seems that childhood gender dysphoria is a necessary but not sufficient factor in prediciting eventual transsexual outcome. The strength, rigidity, and persistence of cross-gender behaviour through latency are thought perhaps to predict transsexual outcome (Davenport 1986).

\section{Change of social gender role}

As mentioned earlier, reversible changes should precede irreversible changes. It follows from this that the first step should be a change of social gender role. This involves the patient changing their name to one clearly appropriate to their preferred gender role, and altering all their associated civil and legal documentation. They should make it clear to everyone that they have changed their social gender role. In the UK, people doing this are protected from discrimination in the workplace and elsewhere by the Sex Discrimination Act 1975.

There is no evidence that providing hormone treatment before a change of social gender role makes such a transition easier or more likely. Rather, it may give rise to a seemingly endless drive for an ever higher dose of hormones, each increase failing to diminish the patient's anxieties about changing role. If the change of role does not occur, or the desire to change role dissipates (as it may, even when a patient has been certain that it will not), the patient will be left with unwanted, irreversible bodily alterations (Barrett 2007b). Consequently, it is reasonable to undertake treatment with cross-sex hormones only if both a proper diagnosis has been made by appropriately trained and experienced clinicians and a change of social gender role has been satisfactorily achieved. Clearly, such treatment varies depending on the biological sex of the patient at birth.

\section{Hormone therapy}

High-dose oestrogen therapy

The mainstay of treatment in male patients is high-dose oestrogen therapy. This treatment seems entirely safe (standardised mortality ratio is 1.0 ) provided patients are non-smokers and have no history of thromboembolic disease, since the major risk is that of thromboembolic problems (van Kesteren 1997; Seal 2007). In younger patients it may need to be augmented by a gonadotrophinreleasing hormone analogue to suppress native androgen production. This is preferred to cyproterone acetate, because cyproterone acetate may cause deranged liver function tests, depression, lethargy and fatigue - seemingly more common in the context of gender identity disorders than that of prostate cancer (Seal 2007).

The oestrogen dose should be increased progressively over about a year to maximise eventual breast size. The use of high doses from the outset is associated with rapid onset of breast growth, but early ductal fusion and the eventual development of small, hard, conical breasts whose size cannot be increased by any further hormonal manipulation (Seal 2007).

This treatment requires 6-monthly monitoring of serum lipids, prolactin and liver function tests since, rarely, these may be deranged.

There is no role for progesterone because it seems not to have any feminising effect, and probably serves to slightly raise the risk of breast cancer (Seal 2007).

Oestrogen treatment causes modest breast development, and even more modest reduction in facial hair growth. Androgen levels usually fall, and the libido further diminishes (usually a welcome effect). Appetite is increased, and so weight gain is a common problem. There is no change in vocal quality, so speech and language therapy may be indicated (Antoni 2007). If this is not fully successful, it may be augmented with cricothyroid approximation surgery to alter vocal quality (Sandhu 2007). This procedure should be followed up with further speech and language therapy.

Born-male patients display feminisation on top of an earlier masculinisation caused by puberty. Consequently, most end up looking sufficiently female that, if they present in a clearly female role, others feel inclined to treat them as women. Nevertheless, nearly all would be detectable as having been born male.

\section{Androgen therapy}

Female patients require treatment with androgens, either by implant or by intramuscular injection. Oral treatment is anecdotally associated with a raised rate of hepatocellular carcinoma. It is thus ethically and legally challenging to use oral agents (Seal 2007). 
Androgen treatment causes marked virilisation. The first effect is an increase in libido, followed by cliteromegaly and facial and body hair growth. Vocal pitch steadily decreases to that of a male. Menstruation almost always becomes less frequent, and menopause is usually achieved within the first 6 months of treatment. Androgens also increase appetite, and so weight gain may be a problem. Muscle mass only increases if there is considerable exercise (Seal 2007).

Androgen treatment is very effective, and most born-female patients end up so masculinised that others would not suspect that they were born female save, perhaps, for unusual shortness of stature.

Although it is inappropriate for hormone treatment to start without the assessment and approval of a properly established gender identity clinic, it is best for prescription and administration to occur in a primary care setting because such treatment will be lifelong and is not challenging or hazardous. The lack of a UK licence for all treatments except for the testosterone propionate Sustanon ${ }^{\circledR}$ reflects not danger but the prohibitive costs of seeking a licence for a low-volume treatment.

\section{Surgery}

Real-life experience

Surgical procedures are not contemplated unless patients have lived and prospered in their assumed gender role, showing psychological and social function that is at least as good as in their former role, and preferably better. A useful means of determining this is noting whether they can undertake an occupational role (consistent with their abilities) for at least a year. This can be verified, and gives a good measure of social acceptance in the new gender role. It is sometimes termed 'the real-life experience' (Barrett 2007c).

Regular, reasonably frequent psychological review is required throughout the real-life experience, carried out by very experienced clinicians rather than primary care or a community mental health team because it is in the setting of a real-life experience that the patient's resolve to live in the other gender role is pitted against the travails of daily life. Patients should be seen to thrive in their new gender role and be clearly able to do so for the foreseeable future. It is very worrying if patients are hanging on to a life in their new gender role only by a whisker, and have no plans for how they will manage after gender reassignment surgery. Patients who have thrived in the very long term describe gender reassignment surgery as having been 'the icing on the cake' and emphasise how important it was to have a good-quality 'cake of life' to add that icing to.

\section{Mastectomy}

Born-female patients may sometimes be considered for bilateral mastectomy after having lived in a male role for a year, whether or not they have been occupied (in education, training, or paid or voluntary employment), because large breasts are a significant impediment to passing successfully as male. This procedure is not cosmetic in the sense that most breast surgery for non-malignant conditions is. Rather, it is more akin to surgery for severe and intractable gynaecomastia in a born male. The psychological and social benefits of bilateral mastectomy in this context are considerable (Davies 2007).

\section{Gender reassignment}

Genital surgery varies depending on the biological sex of the patient at birth. It is not contemplated until there has been a successful life in the assumed gender role for at least 2 years.

Genital surgery for born males always includes the following:

- penectomy

- bilateral orchidectomy

- cliteroplasty

- vulvoplasty.

Vaginoplasty is usually included, but patients who have no desire for penetrative sexual relations, or no desire to form any sort of sexual relationship at all (particularly if older or in less good health) may be better served by this procedure being omitted. The absence of a vagina could only be detected by the most detailed of genital inspections (Bellringer 2007).

These procedures are usually completed in one stage, with the occasional need for very minor revisional procedures. Hospital in-patient stay is typically 10 days, with a convalescence of 2 months (Barrett 2007d). The results are very successful (Barrett 2007e). At least one patient has been undetected by her general practitioner and by her boyfriend of 9 years. Another was undetected in the course of several lesbian relationships.

Genital surgery for born-female patients (phalloplasty) is much more complex, and usually comprises multiple stages. The new phallus must be constructed using tissue from another part of the body. Usually the abdominal or forearm skin is used. Placing a urinary conduit in the phallus is challenging. Erectile capacity can only be bestowed by means of implanted hydraulic devices, and this, too, is challenging (Ralph 2007).

The results of phalloplasty are improving all the time, but the phallus would still be detected as an artificial construction by any but the briefest 
of glimpses. Only about a third of born-female patients opt for phalloplasty, the remainder choosing to wait until techniques improve or until their life circumstances will allow the time off work that such surgery inevitably entails.

As patient numbers have grown, it has become possible to properly assess the psychological and social outcomes of genital surgery and to relate these to features of the patients' presenting histories.

The effects of a social gender role change and the timing of surgery were addressed by fully controlled studies, which established that a change of role improved psychological function, and that once patients had been approved for surgery, those fast-tracked showed better psychological function than those who joined a standard waiting list (Mate-Kole 1990).

The functional results of gender reassignment surgery have been assessed in both sexual and cosmetic terms. In general, patients expressed satisfaction with the quality of cosmetic and functional aspects, even though orgasmic capacity after gender reassignment surgery declined in bornmale patients and increased in those born female (Rehman 1999). Despite the decrease in orgasmic capacity after male-to-female reassignment, satisfaction with sex and general satisfaction with the results of surgery were high in both born-male and born-female patients (Blanchard 1987).

There have been good outcomes in very disparate settings (Kuiper 1988; Rakic 1996) and the strong suggestion from several studies that the technical success of surgery and a subsequent legal recognition of a change of sex relates strongly to good psychological and social outcomes (Stein 1990; Tsoi 1995)

\section{Psychological support}

It seems increasingly clear that psychological support is needed after surgery to optimise outcomes since social stressors may persist despite treatment, particularly if the patient has children (Rehman 1999). There is no evidence that a change of parental gender role has any effect on the sexual development of children (Green 1978). Despite this, many patients have experienced restricted access to their children on the grounds of their change of gender role.

Analysis suggests that born-female patients tend generally to fare better than born-male patients. Whatever their birth sex, patients' regrets about gender reassignment surgery are associated with poor family and friend support, a lack of a history of childhood gender identity disorder, a lack of attraction to the same biological birth-sex, personality disorder and Axis II diagnoses (Bodlund 1996; Landen 1998). Completed military service, a history of typically masculine, physically demanding work and a comparatively late (more than 30 years of age) first request for surgery were also found to be negative prognostic factors in sex reassignment evaluations for born-male patients. It was thought that both too much and too little ambivalence may suggest a poor prognosis (Lindemalm 1987).

\section{Gender recognition certificate}

The Gender Recognition Act 2004 allows people who have changed their gender role to acquire a gender recognition certificate and, if they have a UK birth certificate, a birth certificate in their assumed gender. Applicants must have the support of a recognised specialist and another registered medical practitioner (usually their general practitioner) and need to have lived in their assumed gender role for at least 2 years. They are not absolutely required to have undergone hormone treatment or gender reassignment surgery, but there seems to be a need for a good reason for not having done so. Applications are made to the Gender Recognition Panel (www.grp.gov.uk).

Anyone with a gender recognition certificate is legally of their new sex, just as if they had been born so. However, if they have children, they will be a parent in their sex at birth. If they adopt, they do so in their new sex, so it would be possible for someone to be both a father and a mother.

\section{Implications for practice}

Gender identity disorders are not often encountered in general psychiatric practice. The most frequent is dual-role transvestism, but it rarely needs medical attention. The rarest of the disorders, transsexualism, attracts the most public attention. Gender identity disorders are not automatically indicative of serious psychopathology, but political correctness should not blind assessors to either this possibility, or that the apparent gender identity disorder is the manifestation of another physical or psychological condition.

This complexity, along with considerable potential for disaster resulting from the drastic nature of the interventions, suggests that diagnoses should be made by a gender identity clinic, and never by the patient. Almost invariably a clear change of gender role should precede any hormone treatment, although bilateral mastectomy might be considered after a year of life in a male role. Patients should have lived and thrived entirely in their new gender role for at least a year, and usually 2 years, before any genital surgery is contemplated. 
With this selection regime, prognosis is generally rather good. After treatment, patients may now legally change their sex. It is reassuring to note that many applicants for this legal process changed their gender role several decades before and continue to thrive.

\section{References}

Antoni C (2007) The role of the speech and language therapist. In Transsexual and Other Disorders of Gender Identity: A Practical Guide to Management (ed J Barrett): 139-58. Radcliffe Medical Publishing.

Barrett J (2007a) Dealing with the differentials. In Transsexual and Other Disorders of Gender Identity: A Practical Guide to Management (ed J Barrett): 3-52. Radcliffe Medical Publishing.

Barrett $\mathrm{J}$ (2007b) Challenging patients and circumstances. In Transsexual and Other Disorders of Gender Identity: A Practical Guide to Management (ed J Barrett): 55-65. Radcliffe Medical Publishing.

Barrett J (2007c) The real-life experience. In Transsexual and Other Disorders of Gender Identity: A Practical Guide to Management (ed J Barrett): 69-134. Radcliffe Medical Publishing.

Barrett $J$ (2007d) Advice for patients about to undergo gender reassignment surgery. In Transsexual and Other Disorders of Gender Identity: A Practical Guide to Management (ed J Barrett): 221-4. Radcliffe Medical Publishing.

Barrett J (2007e) Relationships. In Transsexual and Other Disorders of Gender Identity: A Practical Guide to Management (ed J Barrett): 249-51. Radcliffe Medical Publishing.

Bellringer J (2007) Surgery for born males. In Transsexual and Other Disorders of Gender Identity: A Practical Guide to Management (ed J Barrett): 199-224. Radcliffe Medical Publishing.

Blanchard R, Legault S, Lindsay WR (1987) Vaginoplasty outcome in maleto-female transsexuals. Journal of Sex \& Marital Therapy 13: 265-75.

Blanchard R, Steiner BW, Clemmensen LH, et al (1989) Prediction of regrets in postoperative transsexuals. Canadian Journal of Psychiatry 34: $43-5$.

Blanchard R (1991) Clinical observations and systematic studies of autogynephilia. Journal of Sex \& Marital Therapy 17: 235-51.

Blanchard R (1993a) Partial versus complete autogynephilia and gender dysphoria. Journal of Sex \& Marital Therapy 19: 301-7.

Blanchard R, Collins PI (1993b) Men with sexual interest in transvestites, transsexuals, and she-males. Journal of Nervous and Mental Disease 181: 570-5

Blanchard R (1993c) Varieties of autogynephilia and their relationship to gender dysphoria. Archives of Sexual Behavior 22: 241-51.

Blanchard R (1993d) The she-male phenomenon and the concept of partial autogynephilia. Journal of Sex \& Marital Therapy 19: 69-76.

Bodlund 0, Kullgren G (1996) Transsexualism general outcome and prognostic factors: a five-year follow-up study of nineteen transsexuals in the process of changing sex. Archives of Sexual Behavior 25: 303-16.

Buhrich N, McConaghy N (1977) The discrete syndromes of transvestism and transsexualism. Archives of Sexual Behavior 6: 483-95.

Cohen-Kettenis PT, van Goozen SH (1997) Sex reassignment of adolescent transsexuals: a follow-up study. Journal of the American Academy of Child \& Adolescent Psychiatry 36: 263-71.

Cole CM, O'Boyle M, Emory LE, et al (1997) Comorbidity of gender dysphoria and other major psychiatric diagnoses. Archives of Sexual Behavior 26: 13-26.

Davenport CW (1986) A follow-up study of 10 feminine boys. Archives of Sexual Behavior 15: 511-7.

Davies D, Stephenson AJ (2007) Breasts. In Transsexual and Other Disorders of Gender Identity: A Practical Guide to Management (ed J Barrett): 201-7. Radcliffe Medical Publishing.
Green R (1978) Sexual identity of 37 children raised by homosexual or transsexual parents. American Journal of Psychiatry 135: 692-7.

Green R, Blanchard R (1995) Gender identity disorders. In Comprehensive Textbook of Psychiatry (6th edn) (eds HI Kaplan, BJ Saddock): 1153-78. Williams and Wilkins.

Haraldsen IR, Dahl AA (2000) Symptom profiles of gender dysphoric patients of transsexual type compared to patients with personality disorders and healthy adults. Acta Psychiatrica Scandinavica 102: 276-81.

Heiman EM, Cao-Van-Lê (1975) Transsexualism in Vietnam. Archives of Sexual Behavior 4: 89-95.

Kuiper B, Cohen-Kettenis $\mathrm{P}$ (1988) Sex reassignment surgery: a study of 141 Dutch transsexuals. Archives of Sexual Behavior 17: 439-57.

Landen M, Walinder J, Lundstrom B (1996) Prevalence, incidence and sex ratio of transsexualism. Acta Psychiatrica Scandinavica 93: 221-3.

Landen M, Walinder J, Hambert G, et al (1998) Factors predictive of regret in sex reassignment. Acta Psychiatrica Scandinavica 97 284-9.

Levine SB (1980) Psychiatric diagnosis of patients requesting sex reassignment surgery. Journal of Sex \& Marital Therapy 6: 164-73.

Lindemalm G, Korlin D, Uddenberg N (1987) Prognostic factors vs. outcome in male-to-female transsexualism. A follow-up study of 13 cases. Acta Psychiatrica Scandinavica 75: 268-74.

Lothstein LM, Levine SB (1981) Expressive psychotherapy with gender dysphoric patients. Archives of General Psychiatry 38: 924-9.

Mate-Kole C, Freschi M, Robin A (1990) A controlled study of psychological and social change after surgical gender reassignment in selected male transsexuals. British Journal of Psychiatry 157: 261-4.

Miach PP, Berah EF, Butcher JN, et al (2000) Utility of the MMPI2 in assessing gender dysphoric patients. Journal of Personality Assessment 75: 268-79.

Rakic Z, Starcevic V, Maric J, et al (1996) The outcome of sex reassignment surgery in Belgrade: 32 patients of both sexes. Archives of Sexual Behavior 25: 515-25

Ralph D, Christopher N (2007) Phalloplasty. In Transsexual and Other Disorders of Gender Identity: A Practical Guide to Management (ed J Barrett): 229-47. Radcliffe Medical Publishing.

Rehman J, Lazer S, Benet AE, et al (1999) The reported sex and surgery satisfactions of 28 postoperative male-to-female transsexual patients. Archives of Sexual Behavior 28: 71-89.

Sandhu G (2007) ENT surgery. In Transsexual and Other Disorders of Gender Identity: A Practical Guide to Management (ed J Barrett): 191-7. Radcliffe Medical Publishing.

Seal LJ (2007) The practical management of hormonal treatment in adults with gender dysphoria. In Transsexual and Other Disorders of Gender Identity: A Practical Guide to Management (ed J Barrett): 157-90. Radcliffe Medical Publishing.

Shtasel TF (1979) Behavioral treatment of transsexualism: a case report. Journal of Sex \& Marital Therapy 5: 362-7.

Smith YL, van Goozen SH, Cohen-Kettenis PT (2001) Adolescents with gender identity disorder who were accepted or rejected for sex reassignment surgery: a prospective follow-up study. Journal of the American Academy of Child \& Adolescent Psychiatry 40: 472-81.

Stein M, Tiefer L, Melman A (1990) Follow-up observations of operated male-to-female transsexuals. Journal of Urology 143: 1188-92.

Tsoi WF, Kok LP, Yeo KL, et al (1995) Follow-up study of female transsexuals. Annals of the Academy of Medicine, Singapore 24: $664-7$.

van Kesteren PJ, Asscheman H, Megens JA, et al (1997) Mortality and morbidity in transsexual subjects treated with cross-sex hormones. Clinical Endocrinology 47: 337-42.

World Health Organization (1992) The ICD-10 Classification of Mental and Behavioural Disorders. WHO. 


\section{MCQs}

Select the single best option for each question stem

1 A 32-year-old married male presents in female clothes, saying that he knows he is transsexual. He wants treatment with oestrogens and has information gained from the internet. Do you:

a commence treatment with an atypical antipsychotic?

b refer for relationship counselling?

c prescribe as he advises?

d refer to a gender identity clinic?

e combine $c$ and $d$ ?

2 A 26-year-old lesbian requests a bilateral mastectomy as the first stage in her plan to live as a man. She has already changed her name to a male name. Do you:

a refer to breast surgeons?

b refer to a gender identity clinic?

c decline - the surgery is not indicated?

$\mathrm{d}$ refer to lesbian support group?

e treat with androgens as a first step?
3 A 40-year-old male presents saying that he is self-administering a small dose of oestrogens bought from the internet, and wants this transferred to a safer, monitored system. Do you:

a refuse?

b comply, but refer to a gender identity clinic?

c measure serum levels to confirm his claim?

$d$ refuse to prescribe but monitor the effects of the treatment and refer to a gender identity clinic?

e increase the dose to the normal hormone replacement therapy level?

4 0ccupational health ask you to see a 30 -year-old male who, it has been found, is spending much of his free time in a female role. He confirms this, and sees no problem with it. Do you:

a agree?

b agree, and suggest treatment with hormones?

c take the view that this is a disciplinary and not a medical matter? d insist on an opinion from a gender identity clinic?

e tell him he must desist?

5 In the course of a forensic assessment of a woman charged with shoplifting, it emerges that she was born a man, but has undergone hormone treatment and surgery and has lived as a woman for 10 years. She has a gender recognition certificate. In your report, do you:

a make this plain, but point out that it is of no relevance?

b make no mention of it?

c mention it - shoplifting varies with gender, after all?

d simply include it as background detail? e seek the patient's permission to mention it? 